\title{
Optimal Inventory Policy under Permissible Payment Delay in Fashion Supply Chains
}

\author{
Guo Li, ${ }^{1,2}$ Yuchen Kang, ${ }^{1,2}$ Mengqi Liu, ${ }^{3}$ and Zhaohua Wang ${ }^{1,2}$ \\ ${ }^{1}$ School of Management and Economics, Beijing Institute of Technology, Beijing 100081, China \\ ${ }^{2}$ Center for Energy and Environmental Policy Research, Beijing Institute of Technology, Beijing 100081, China \\ ${ }^{3}$ School of Business Administration, Hunan University, Changsha 410082, China \\ Correspondence should be addressed to Mengqi Liu; 1069679071@qq.com
}

Received 11 February 2014; Accepted 2 April 2014; Published 8 May 2014

Academic Editor: Xiaohang Yue

Copyright (c) 2014 Guo Li et al. This is an open access article distributed under the Creative Commons Attribution License, which permits unrestricted use, distribution, and reproduction in any medium, provided the original work is properly cited.

\begin{abstract}
This paper investigates a retailer's optimal inventory cycle and the corresponding time of payment in fashion supply chains where a supplier allows the payment delay. Here according to the established model we first analyze the retailer's reaction, and then find out the retailer's optimal inventory policy and time of payment to maximize its total profit. Our result shows that it is not always the best choice for retailers of fashion supply chains to choose the discount way to replenish stocks, but the retailer can decide the optimal credit period and inventory cycle. Moreover, numerical examples are provided to illustrate the model's feasibility and rationality.
\end{abstract}

\section{Introduction}

With the fast development of economy, fashion industry develops rapidly in China and occupies an important position [1]. As a result, the operational issues in fashion supply chains are attracting more and more researchers' attention. Most efforts have been made in coordination of a fashion supply chain with demand variations, pricing, quantity discounts, and risk management $[2,3]$, while this paper focuses on the credit period problem in the fashion supply chain.

Considering the value of time, more businessmen realize that the time paying for the goods is crucial for them. In fashion supply chains, aiming to receive the payment in time, suppliers usually provide a set of credit periods for retailers. The benefits of this permissible payment delay not only attract new buyers who regard it as a way of reducing the purchasing cost, but also provide a competitive strategy for suppliersnot cutting down the wholesale price only. But on the other hand, credit period increases the operational cost as well as the default risk to suppliers. In order to decrease the total cost and credit risk, suppliers are more likely to offer different credit periods for different quantities the retailers purchase. Up to now many scholars have explored suppliers' optimal decisions in credit period rather than considering it from the perspective of retailers. For example, questions of how should suppliers decide the optimal credit period facing discount and payment time and what kind of corresponding inventory policy is the optimal for retailers under such conditions are seldom considered [4]. Hence, how to lower the opportunity cost and choose the optimal inventory cycle time in the process of procurement become important issues for retailers in business industry when they confront different credit periods [5]. After that we also consider the coordination problem in fashion supply chains. Is there any other kind of coordination in fashion supply chains, without contract and easier to implement? In reality, there are more business industries facing these problems.

For example, the fashion retailer Metersbonwe who outsources garment processing business faces the issue of how to reach the optimal credit period. In addition, the phenomenon of the supplier dominating over the retailer or the opposite is particularly prominent in this industry. A dominant retailer, such as Wal-Mart, has the "power" to delay the payment for goods and to share losses with suppliers [6]; in contrast, a dominant supplier, such as the fashion supplier Li-Ning, has the "power" to make the delivery only after payment and so forth. The dominant side often gets more profits, but this kind of extra profit gaining is mostly from the profit decrease of the other side; therefore, there is no profit improvement in the whole supply chain. Thus the cooperation of both 
sides is proposed to get a win-win situation. Yet, cooperation is very difficult to realize in its real sense for a long time which is just like the prisoner dilemma [7]. We can see from the price war in the television industry that all the TV sellers agree not to reduce the price at first, but finally they seldom jump out of the vicious cycle of price war [8]. So this paper proposes a method of cooperation in which both sides rationally pursue profit maximization under no restriction of cooperation contract. And assumes that they follow the scientific, advanced, economical, and credit principle to achieve the lowest cost without violating regulations (such as credit requirements) and intend to maximize human, financial, and material resources utilization. In the following parts, we analyze the retailer's profit in the above situation and compare it with another situation in which both sides sign a cooperation contract to maximize the profit of the entire fashion supply chain.

So this paper mainly investigates credit period mechanism with discount issue between supplier and retailer in the fashion supply chain and their inventory optimization problems and then makes proposals to solve the cooperation issue. To address these problems, the paper sets out to answer the following questions.

(1) Given that the supplier provides credit periods with discount for price, what is the optimal strategy (decisions about the optimal inventory cycle and credit period) for the retailer?

(2) Should the supplier set different credit periods and how?

(3) Under the condition of credit periods with discount, what is the difference between individually pursuing profit maximization rationally and pursuing profit maximization under cooperation contract for the retailer?

The rest of this paper is organized as follows: Section 2 presents a review of the related literature. Assumptions and notations are given in Section 3 and an optimization model for retailer's inventory cycle time under permissible payment delay and price discount in fashion supply chains is established. Section 4 provides a detailed solution procedure. Section 5 gives the retailer's optimal decision for credit period and inventory cycle time and designs a heuristic algorithm for optimization of this comprehensive model. Numerical examples and discussions are presented in Section 6 and finally conclusions are given in the last section.

\section{Literature Review}

Now credit period is an important topic in fashion supply chains. The existing researches on this issue have achieved a lot in the process of building mathematical models, considering some influence factors and then getting the optimal strategy, all of which provide the theoretical foundation for the development of fashion supply chains.

The earliest contribution of credit policy is from Goyal [9]. He is the first one to investigate the retailer's optimal EOQ under the condition of allowing deferred payment. Soon afterwards more researchers conduct comprehensive and detailed studies on the payment time. For instance, Jaggi and Aggarwal [10] study credit financing in economic ordering policies of deteriorating items on the basis of Goyal's study. Kim et al. [11] propose an optimal credit policy to increase supplier's profit with price-dependent demand functions. Khouja and Mehrez [12] suggest that the supplier can provide two different ways of payment. Cheng et al. [13] further present the retailer's optimal inventory policy under different supplier credit policies. These studies provide a theoretical basis and direction for the study of fashion supply chain's credit period mechanism. Then this paper mainly reviews the literatures from three aspects, which are discount strategy, inventory policy, and the cooperation between the retailer and the supplier.

Firstly, the literature on credit policy coordination mostly includes ordering quantity into models. Jamal et al. [14], Chang et al. [15], Chung and Liao [16], and Chung et al. [17] find the best time of payment and optimal order policy of the retailer under the condition of allowing payment delay (if ordering quantity is large enough). They make a limit on the delay payment, namely, only retailers who order up to a certain quantity can be given the right to delay payment in order to balance the interests of both sides. They fully consider the importance of capital's opportunity cost, guiding the direction for later researches and attracting enterprises' attention to the opportunity cost of funds. Then Chung [18] sums up a theorem on the determination of economic order quantity under conditions of permissible delay in payments. Besides, many researchers like Liping et al. [19], Lee and Rhee [20], and Zhong and Zhou [21] analyze how to set up the credit period mechanism and quantity discount from the aspect of suppliers. Based on existing studies, Chang [22] establishes an extended EOQ model with cash discount and payment delay. These make researches on credit period issues more subdivided, specific and closer to realistic environment.

After this many researchers has done further studies on retailer's optimal inventory model and ordering strategy under the condition of suppliers providing the credit period [23-29]. Huang [30] investigates both the retailer's optimal ordering strategy and payment strategy under the condition of suppliers providing the credit period. Chung and Huang [31] examine the optimal cycle time for EPQ inventory model under permissible delay in payments. He is the first one to state in his research that providing credit to consumers stimulates consumption, which determines the optimal replenishment quantity. Chang and Teng [32] put forward an optimal order strategy for retailers in which the discount provided by suppliers could not only avoid default risks but also allow delaying payment, which increases sales. To sum up, earlier researchers mainly focus on the relationship among the retailer's optimal replenishment quantity, ordering strategy, and credit period mechanism.

At last, we explore the cooperation of the retailer and the supplier in the fashion supply chain. About the cooperation, we assume that the retailer tends to cooperate with the supplier with a reasonable time of payment, without signing a contract. Huang [33] makes an important research on the credit problem in the entire supply chain where the retailer 
is the dominator. Li and Liu [34] and Liping and Xiaoyuan [35] advocate the cooperation of retailer and supplier, which promotes profits of the entire supply chain. And they also analyze supply chain profit sharing issues in the case of credit period. Su et al. [36] make a breakthrough in that they consider the retailer's optimal decision while taking the optimal supplier's delivery strategy into account. For the first time, by analyzing the total channel profit function, an algorithm is proposed to determine the retailer's optimal order quantity and simultaneously calculate the number of shipments per production running from the supplier to the retailer. Most recently in 2012, Cheng et al. [37] conduct a new study on the optimal order strategy for retailers to cope with changing situations. These above researchers mainly study how to increase the profit from the perspective of the overall efficiency of the supply chain and propose the benefit-sharing approach to stimulate cooperation. But this paper studies the problem by considering them, respectively. So is there a way to achieve the same effect of the traditional cooperation without signing the cooperation contract? We figure out the answer in this paper.

Based on the above references, we can see few studies investigating the inventory cycle and the credit period, even less taking the time value of money into account, not to mention considering these in fashion supply chains. Therefore, the paper refines credit policy to the supplier further and establishes and deduces the mathematical model about the retailer's optimal inventory cycle and time of payment with the discount given. It not only considers the time value of money caused by the advance or delay of the retailer's delivery period, but also considers time value of money incurred from retailer's inventory changing. Finally, numerical examples are presented to prove the conclusion's authenticity and operability. Compared with existing study (Ho et al. (2008) [38]), we have explored further the fundamental problem of the cooperation between retailer and supplier and its influence to the whole supply chain if the retailer delays payment or borrows money from external sources.

So the following two main questions are considered. First, how should the retailer decide his inventory cycle and time of payment when the supplier provides two different credit periods in fashion supply chains? Second, how will retailer's rational individual action influence the cooperation between the retailer and supplier?

\section{Model Description and Formulation}

\subsection{Assumptions and Notations}

\subsubsection{Assumptions}

(1) There are only a single supplier and a single retailer in the fashion supply chain.

(2) There is no consideration of the stock-out situation and the retailer has a fixed order cycle to order goods.

(3) The supplier gives the retailer different payment deadlines, namely, different credit periods. In the credit period, the retailer acquires a certain interest from sales revenue. And upon arrival deadline, the retailer must pay for goods.

(4) The retailer is given $\alpha$ discount on price, paying the products before the period of $M_{1}$. Otherwise, if the time of payment is after $M_{1}$ and before $M_{2}$ the retailer will not be entitled to the discount. Due to the opportunity cost, the retailer will pay in the final period regardless of the way he/she chooses, which means the retailer chooses to pay in $M_{1}$ period if there is discount and chooses to pay in $M_{2}$ if there is no discount $\left(M_{1}<M_{2}\right)$. Meanwhile, we assume that the bank interest is less than the capital rate of opportunity cost according to the market situation (namely, the profit obtained from investment is more than making deposits in bank).

Notations and major variables are shown in Definition of Parameters and Variables Section at the end of the paper.

3.2. Model Formulation. The model for the solution of the retailer's final profit is mainly composed of the following aspects. (1) $S$ is the ordering cost in the ordering process and accordingly the ordering cost per unit time is $S / T$. (2) $P_{2}$ is the cost of each unit product paid by the retailer and meanwhile there will be the inventory cost, which can be calculated by $\int_{0}^{T} h D(T-t) d t=(1 / 2) h D T^{2}$ and it decreases with time in the sale process. So the inventory cost per unit time is $(1 / 2) h D T$. (3) The opportunity cost or investment income due to the variance in payment time is different. Hereon, we consider two cases: $T<M_{i}$ and $T \geq M_{i}, i=1,2$, which are depicted in Figure 1.

(1) When $T<M_{i}, i=1,2$. In this case, the retailer would pay after all inventories are consumed. So the retailer does not suffer from the opportunity cost because of no payment in advance and instead he/she can use the sales for investment in the $M_{i}-T$ period to get some income from investment. Hence, the interest earned per unit time in the model is

$$
\frac{\int_{0}^{T} P D t I_{r} d t+P D T I_{r}\left(M_{i}-T\right)}{T}=\frac{1}{2} P D T I_{r}+P D I_{r}\left(M_{i}-T\right) .
$$

Through our analysis, we could get the profit model for this case of the retailer as follows:

$$
\begin{aligned}
\Pi_{r i 1}= & \frac{P D T}{T}-\frac{S}{T}-\frac{P_{s}\left(1-K_{i} \alpha\right) D T}{T} \\
& -\frac{\int_{0}^{T} h D(T-t) d t}{T}+\frac{\int_{0}^{T} P D t I_{r} d t+P D T I_{r}\left(M_{i}-T\right)}{T} \\
= & P D-\frac{S}{T}-P_{s}\left(1-k_{i} \alpha\right) D-\frac{1}{2} h D T \\
& +\frac{1}{2} P D T I_{r}+P D I_{r}\left(M_{i}-T\right) .
\end{aligned}
$$




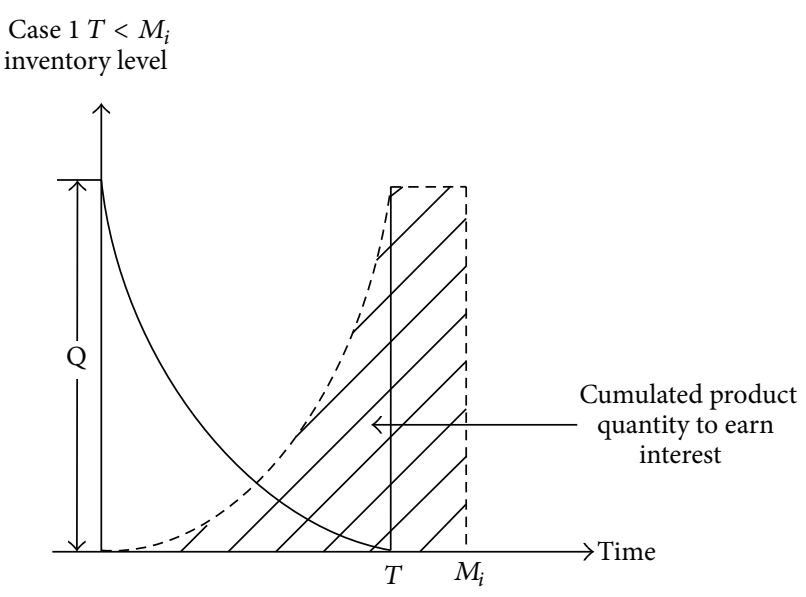

(a)

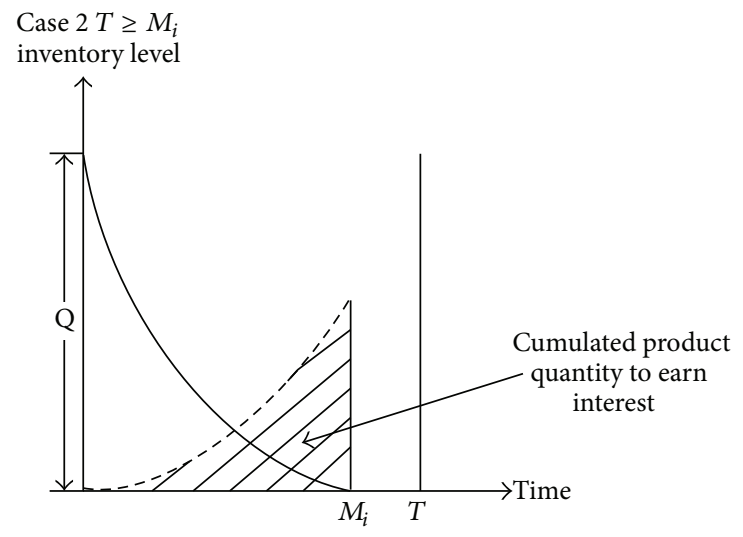

(b)

FIGURE 1: The retailer's inventory and investment model under credit period.

(2) When $T \geq M_{i}, i=1,2$. In Figure 1, we could get the fact that the retailer payment period is shorter than inventory cycle, which means the retailer needs to pay before all products are sold out. So compared with case 1, less inventory income but certain opportunity cost will generate during the period of $T \geq M_{i}$.

This part is shown as

$$
\begin{gathered}
\frac{\int_{0}^{M_{i}} P D t I_{r} d t}{T}-\frac{\int_{M_{i}}^{T} P_{s}\left(1-k_{i} \alpha\right) D I_{r}\left(t-M_{i}\right) d t}{T} \\
=\frac{P D M_{i}^{2} I_{r}}{2 T}-\frac{P_{s} D I_{r}\left(1-k_{i} \alpha\right)\left(T-M_{i}\right)^{2}}{2 T} .
\end{gathered}
$$

In sum, the profit model in this case could be constructed as follows:

$$
\begin{aligned}
\Pi_{r i 2}= & \frac{P D T}{T}-\frac{S}{T}-\frac{P_{s}\left(1-k_{i} \alpha\right) D T}{T}-\frac{\int_{0}^{T} h D(T-t) d t}{T} \\
& +\frac{\int_{0}^{M_{i}} P D t I_{r} d t}{T}-\frac{\int_{M_{i}}^{T} P_{s}\left(1-k_{i} \alpha\right) D I_{r}\left(t-M_{i}\right) d t}{T} \\
= & P D-\frac{S}{T}-P_{s}\left(1-k_{i} \alpha\right) D-\frac{1}{2} h D T+\frac{P D M_{i}^{2} I_{r}}{2 T} \\
& -\frac{P_{s} D I_{r}\left(1-k_{i} \alpha\right)\left(T-M_{i}\right)^{2}}{2 T} .
\end{aligned}
$$

So the supplier's profit model can be concluded as follows:

$$
\begin{gathered}
\Pi_{r i}(T)= \begin{cases}\Pi_{r i 1}(T), & \text { if } T<M_{i}, \\
\Pi_{r i 2}(T), & \text { if } T \geq M_{i},\end{cases} \\
i=1,2 ; k_{1}=1, k_{2}=0 .
\end{gathered}
$$

The problem now is to determine the optimal values of $T$ and $M$ that maximize $\Pi_{r i}(T), i=1,2$, in formula (5).

\section{Optimal Decision}

To get the optimal $T$ and $M$, firstly we analyze formula (2) in the following steps.

Taking the first derivative of formula (2), we can get

$$
\frac{\partial \Pi_{r i 1}}{\partial T}=-\frac{1}{2} h D+\frac{1}{2} P D I_{r}-P D I_{r}+\frac{S}{T^{2}} .
$$

Then, solving its second derivative, we obtain

$$
\frac{\partial^{2} \Pi_{r i 1}}{\partial^{2} T}=-\frac{2 S}{T^{3}}<0 .
$$

Hence, $\Pi_{r i 1}(T)$ is a concave function in $T$. Consequently, there exists a unique value of $T$, denoted by $T_{i 1}^{*}$, which maximizes the value of $\Pi_{r i 1}(T)$.

$T_{i 1}^{*}$ can be obtained by solving the equation $\partial \Pi_{r i 1} / \partial T=0$ and is given by

$$
T_{i 1}^{*}=\sqrt{\frac{2 S}{h D+P D I_{r}}} .
$$

To insure $T_{i 1}^{*}<M_{i}$, we substitute formula (8) into $T_{i 1}^{*}<$ $M_{i}$ and obtain the following.

If and only if $T_{i 1}^{*}<M_{i}$, then

$$
T_{i 1}^{*}=\sqrt{\frac{2 S}{h D+P D I_{r}}}<M_{i} \Longrightarrow 2 S<\left(h D+P D I_{r}\right) M_{i}^{2} .
$$

Furthermore, from formula (9), we have the following. If and only if $T \geq M_{i}$, then $2 S \geq\left(h D+P D I_{r}\right) M_{i}^{2}$.

Take the first derivative to formula (4):

$$
\begin{aligned}
\frac{\partial \Pi_{r i 2}}{\partial T}= & -\frac{1}{2} h D+\frac{S}{T^{2}}-\frac{P D I_{r} M_{i}^{2}}{2 T^{2}} \\
& -\frac{P_{s}\left(1-k_{i} \alpha\right) D I_{r}\left(T^{2}-M_{i}^{2}\right)}{2 T^{2}} .
\end{aligned}
$$


Then take the second derivative:

$$
\frac{\partial^{2} \Pi_{r i 2}}{\partial^{2} T}=-\frac{1}{T^{3}}\left[2 S-P D I_{r} M_{i}^{2}+P_{s}\left(1-k_{i} \alpha\right) D I_{r} M_{i}^{2}\right] .
$$

Note that

$$
\begin{aligned}
2 S & -P D M_{i}^{2} I_{r}+P_{s}\left(1-k_{i} \alpha\right) D I_{r} M_{i}^{2} \\
& \geq\left(h D+P D I_{r}\right) M_{i}^{2}-P D M_{i}^{2} I_{r}+P_{s}\left(1-k_{i} \alpha\right) D I_{r} M_{i}^{2} \\
& =h D M_{i}^{2}+P_{s}\left(1-k_{i} \alpha\right) D I_{r} M_{i}^{2} \\
& >0 .
\end{aligned}
$$

It can be shown that

$$
2 S-P D M_{i}^{2} I_{r}+P_{s}\left(1-k_{i} \alpha\right) D I_{r} M_{i}^{2}>0,
$$

which implies that the second derivative of $\Pi_{r i 2}(T)$ is

$$
\frac{\partial^{2} \Pi_{r i 2}}{\partial^{2} T}<0
$$

Therefore, $\Pi_{r i 2}(T)$ is a concave function in $T$. By solving the formula $\partial \Pi_{r i 2} / \partial T=0$, we can get the optimal $T_{i 2}^{*}$, which maximizes $\Pi_{r i 2}(T)$ :

$$
T_{i 2}^{*}=\sqrt{\frac{2 S-P D M_{i}^{2} I_{r}+P_{s}\left(1-k_{i} \alpha\right) D I_{r} M_{i}^{2}}{h D+P_{s}\left(1-k_{i} \alpha\right) D I_{r}}} .
$$

\section{Solution Procedure}

From the above analysis, conclusions can be drawn as follows.

Proposition 1. When $T<M_{i}$ and $P I_{r}\left(M_{2}-M_{1}\right)-P_{s} \alpha \geq$ 0 , that is, when sales revenue of single product exceeds the discount offered, the retailer should pay in $M_{2}$; otherwise, he/she should pay at $M_{1}$.

Proof. From formula (8), we know that the value of $T_{i 1}^{*}$ has nothing to do with $M_{i}$, which means that the values of $T_{11}^{*}$ and $T_{21}^{*}$ are the same. Substituting $T_{11}^{*}$ and $T_{21}^{*}$ into $\Pi_{r i 1}$, we can get $\Pi_{r 21}-\Pi_{r 11}=D\left[P I_{r}\left(M_{2}-M_{1}\right)-P_{s} \alpha\right]$. When $P I_{r}\left(M_{2}-\right.$ $\left.M_{1}\right)-P_{s} \alpha \geq 0$, we know $\Pi_{r 11} \leq \Pi_{r 21}$, so the retailer should pay at $M_{2}$; on the other hand, when $P I_{r}\left(M_{2}-M_{1}\right)-P_{s} \alpha<0$, we know $\Pi_{r 11}>\Pi_{r 21}$, which implies that the retailer should pay at $M_{1}$. Therefore, we can obtain Proposition 1.

Proposition 2. When $2 S<\left(h D+P D I_{r}\right) M_{1}^{2}$, if $\max \left(\Pi_{r 11}\right.$, $\left.\Pi_{r 21}\right)=\Pi_{r 21}$, the optimal time of payment is $M_{2}, T^{*}=T_{21}^{*}$. Or else, the optimal time of payment is $M_{1}, T^{*}=T_{11}^{*}$.

Proof. From formula (9), we can get $T_{i 1}^{*}=$ $\sqrt{2 S /\left(h D+P D I_{r}\right)}<M_{i}$, when $2 S<\left(h D+P D I_{r}\right) M_{i}^{2}$. Similarly, we can get $T_{i 1}^{*}=\sqrt{2 S /\left(h D+P D I_{r}\right)}<M_{1}$, when $2 S<\left(h D+P D I_{r}\right) M_{1}^{2}$. That is to say, it is likely that both $T_{11}^{*}$ and $T_{21}^{*}$ are less than $M_{1}$. Under the premise of choosing optimal profit, we should compare the profit of the retailer brought by $T_{11}^{*}$ and $T_{21}^{*}$, respectively. This result can be drawn from Proposition 1, so Proposition 2 is obviously correct.
Proposition 3. When $\left(h D+P D I_{r}\right) M_{1}^{2} \leq 2 S<(h D+$ $\left.P D I_{r}\right) M_{2}^{2}$, if $\max \left(\Pi_{r 12}, \Pi_{r 21}\right)=\Pi_{r 12}$, the optimal time of payment is $M_{1}, T^{*}=T_{12}^{*}$. If not, the optimal time is $M_{2}$, $T^{*}=T_{21}^{*}$.

Proof. The proof is the same with Proposition 2.

Proposition 4. When $2 S \geq\left(h D+P D I_{r}\right) M_{2}^{2}$, if $\max \left(\Pi_{r 12}\right.$, $\left.\Pi_{r 22}\right)=\Pi_{r 12}$, the optimal time of payment is $M_{1}, T^{*}=T_{12}^{*}$. Otherwise, the optimal time of payment is $M_{2}, T^{*}=T_{22}^{*}$.

Proof. The proof method is the same with Proposition 2.

Our algorithm:

(1) Give the parameters $P_{s}, D, S, I_{r}, h, P, \alpha, M_{i}\left(M_{1}<\right.$ $M_{2}$ ) corresponding value, respectively.

(2) Solve the corresponding values of $T_{i 1}^{*}$ and $T_{i 2}^{*}$ according to formula (9) and (15).

(3) Judgments on,

If $2 S<\left(h D+P D I_{r}\right) M_{1}^{2}$ and $\Pi_{\mathrm{r} 11}<\Pi_{\mathrm{r} 21}$, the optimal payment period is $M_{2}, T^{*}=T_{21}^{*}$. If not, go to the following step.

If $\left(h D+P D I_{r}\right) M_{1}^{2} \leq 2 S<\left(h D+P D I_{r}\right) M_{2}^{2}$, and $\max \left(\Pi_{r 12}\right.$, $\left.\Pi_{r 21}\right)=\Pi_{r 12}$, the optimal time of payment is $M_{1}, T^{*}=T_{12}^{*}$. Otherwise, the optimal time of payment is $M_{2}, T^{*}=T_{21}^{*}$. If it can not meet the condition, go to the following step.

When $2 S \geq\left(h D+P D I_{r}\right) M_{2}^{2}$, if $\max \left(\Pi_{r 12}, \Pi_{r 21}\right)=\Pi_{r 12}$, the optimal time of payment is $M_{1}, T^{*}=T_{12}^{*}$. Otherwise, the optimal time of payment is $M_{2}, T^{*}=T_{22}^{*}$.

If situations mentioned above are not tenable, it is suggested that the optimal time of payment does not exist at this moment. Then go back to step (1) to reset the parameters' value.

\section{Numerical Analysis}

In order to prove the algorithm above, we assume that the parameters of a certain supply chain are set as below: $P_{s}=$ $\$ 5 /$ unit, $P=\$ 10 /$ unit, $S=\$ 300 /$ order, $\alpha=0.2, M_{1}=10$ days, $M_{2}=30$ days, $I_{r}=0.16 /$ year, $h=\$ 0.1 /$ unit, and $D=15$ units. Under this set of data we can figure out that the optimal inventory cycle time is $T_{21}^{*}=4.85$ days and the optimal time of payment is $M_{2}=30$ days and $P I_{r}\left(M_{2}-M_{1}\right)-P_{s} \alpha \geq$ 0 . The result shows that retailers cannot achieve a maximal profit if they choose the credit period when the supplier offers discount, but choosing the longest credit period can make it. So the result fully demonstrates the correctness of Propositions 1 and 2. Similarly, we can also prove that Propositions 3 and 4 are correct.

With the purpose of analyzing the influence of the credit period change to the retailer's profit, a new set of parameters' value is given as below: $P_{s}=\$ 4 /$ unit, $P=\$ 12 /$ unit, $S=$ $\$ 300 /$ order, $\alpha=0.1, I_{r}=0.14 /$ year, $h=\$ 0.1 /$ unit, and $D=$ 15 units, and the influence on the retailer's profit from the change of $M_{1}$ and $M_{2}$ can be clearly observed in Figures 2 and 3. Further, the values of each parameter are clearly shown in Table 1. 

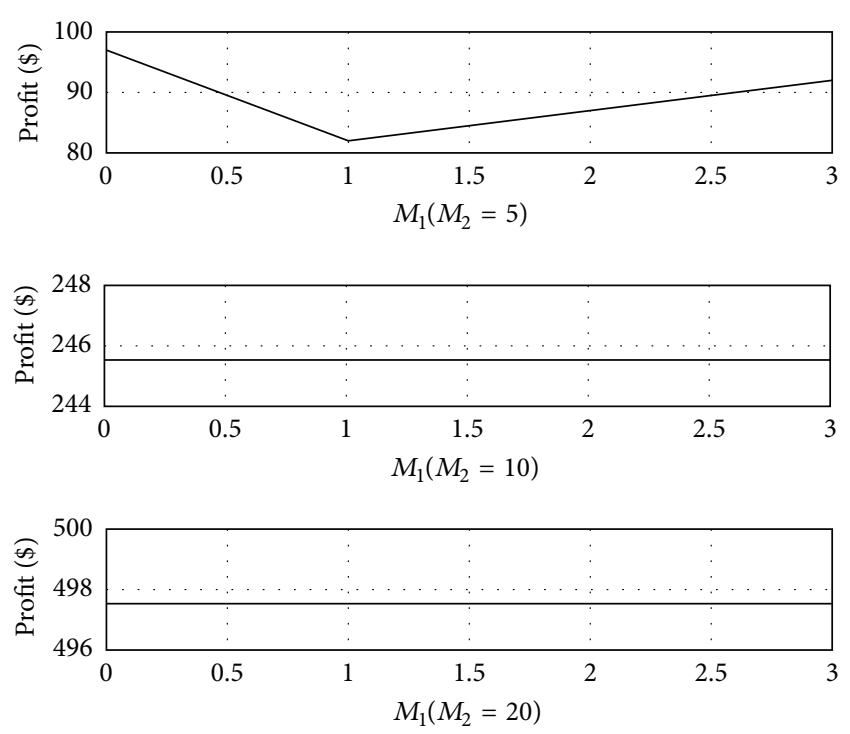

FIGURE 2: Influence of the change of credit period to the retailer's profit.

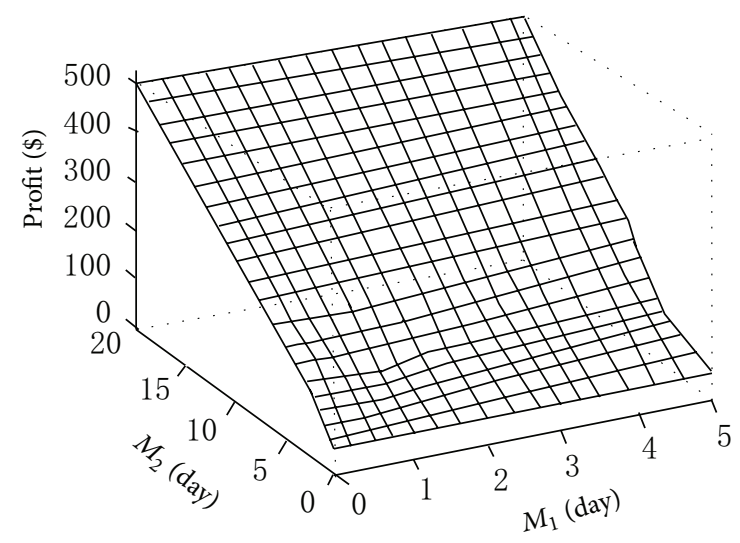

FIGURE 3: Variance of the retailer's profit under different credit periods.

In Table 1, we can see that it has a great influence on the retailer's inventory cycle time and profit when the supplier provides different credit periods. By providing a certain favorable incentive, the supplier can improve the retailer's profit and get the payment earlier, but, to avoid the loss outweighing the gain, the supplier should set reasonable credit period. When the supplier provides a credit period under a certain number of days, the retailer should pay it in time. But if the supplier provides a kind of timely credit period with price discount, the retailer should compare the profits brought by two credit periods, respectively, to make the optimal payment choice.

At the same time, from Table 1, we can know that, under two different kinds of credit periods, the longer the interval time is, the later the final payment deadline should be, which means one should not choose the shorter payment deadline for discount. We also observe that the inventory cycle values are partly same, which means that when $M_{2}$ is big enough, it
TABLE 1: Retailer's optimal performance under various credit periods.

\begin{tabular}{lcccc}
\hline $\begin{array}{l}M_{1} \\
\text { (days) }\end{array}$ & $\begin{array}{c}M_{2} \\
(\text { days })\end{array}$ & $\begin{array}{c}\text { Optimal time } \\
\text { for payment }\end{array}$ & $\begin{array}{c}T^{*} \\
\text { (days) }\end{array}$ & $\begin{array}{c}\text { Profit }(\$) \\
\text { retailer }\end{array}$ \\
\hline 0 & 0 & - & $T=7.785$ & 42.929 \\
\hline 0 & & 5 & $T_{2}=5.784$ & 96.339 \\
1 & 5 & 1 & $T_{12}=8.017$ & 82.568 \\
3 & & 3 & $T_{12}=6.979$ & 91.874 \\
\hline 0 & & 10 & $T_{1}=4.741$ & 245.429 \\
1 & 10 & 10 & $T_{21}=4.741$ & 245.429 \\
3 & & 10 & $T_{21}=4.741$ & 245.429 \\
\hline 0 & & 20 & $T_{1}=4.741$ & 497.429 \\
1 & 20 & 20 & $T_{1}=4.741$ & 497.429 \\
3 & & 20 & $T_{1}=4.741$ & 497.429 \\
\hline
\end{tabular}

will have little impact on the inventory cycle and the profit. And it also suggests that it's not good to get the payment in advance when the maximum credit period reaches a certain number of days. What is interesting is that we find the effect tends to be the same with the study of Ho et al. (2008) [38], which means that the optimal selection of the retailer should be evolved into corporation with the supplier.

The supplier's model is illustrated as

$$
\Pi_{s}=\left\{\begin{array}{l}
P_{s} D T-C D T-P_{s} D T I_{s} M_{2}, \\
(1-\alpha) P_{s} D T-C D T-(1-\alpha) P_{s} D T I_{s} M_{1} \\
\quad+(1-\alpha) P_{s} D T I_{s}\left(M_{2}-M_{1}\right) .
\end{array}\right.
$$

In reality, the equal status between the supplier and the retailer is gradually losing its balance, and the strength and weakness of the fashion supply chain become more apparent. The stronger supplier of supply chain (such as fashion tycoon Nike) and stronger retailer of supply chain (such as WalMart) are gradually emerging. Taking the importance of capital's time value into account, both parties mutually press on payment in order to make the capital rate of their own opportunity cost minimized and maximize the profit, respectively.

From the supplier's model, we learn that the supplier should choose immediate payment when there is a strong supplier, but the retailer's profit is minimal; this moment can be noticed from Table 2 . When there is a strong retailer, the retailer will try to delay the time of payment. This disequilibrium not only leads to unreasonable profit distribution of both sides but also makes the whole supply chain uncoordinated and the profit not maximized (Ho et al. (2008) [38]).

Therefore we bring in the credit period in fashion supply chains to adjust the contradiction between the retailer and supplier. The example is enumerated to prove the necessity of credit period. Use the second set data of parameters in part 6 and let $C=\$ 2 /$ unit; we get Table 2 .

After receiving goods, the retailer generally delays payment for goods without any privilege if the supplier offers no discount. From the following retailer's profit model, we learn that it is beneficial for the retailer but not for 
TABLE 2: The optimal solution between supplier and retailer under different choices.

\begin{tabular}{lccccc}
\hline \multirow{2}{*}{ Decision making } & Credit term(s) & Time for payment & \multirow{2}{*}{$T^{*}$ (days) } & \multicolumn{2}{c}{ Profit (\$) } \\
& & & & Retailer & Supplier \\
\hline \multirow{2}{*}{ Independent } & Cash on delivery & 0 & $T=7.785$ & 42.929 & 233.55 \\
& Credit period (1/1, net 5) & 1 & $T_{12}=8.017$ & 82.568 & 287.734 \\
\hline
\end{tabular}

the supplier, because the increased value of retailer's profit is $k_{i} \int_{0}^{M} P_{s} D T I_{r} d t$ and accordingly the decreased value of supplier is $k_{i} P_{s} D T I_{s} M$ :

$$
\begin{aligned}
& \Pi_{r}= P D T-S-P_{s} D T \\
&-\int_{0}^{T} h D(T-t) d t+k_{i} \int_{0}^{M} P_{s} D T I_{r} d t, \\
& \Pi_{s}=P_{s} D T-C D T-k_{i} P_{s} D T I_{s} M, \\
& \forall i=1,2, \quad k_{i}= \begin{cases}1, & i=1, \\
0, & i=2 .\end{cases}
\end{aligned}
$$

So the supplier should offer some incentives to encourage the retailer to pay in advance.

The interest conflict of both the retailer and the supplier is increasingly fierce, as immediate payment has been unable to balance the interests of both sides. So without the preferential policy, the retailer would delay payment, instead of raising money from outside of the fashion supply chain. We should consider the internal delay and the external borrowing to maximize the profit of whole supply chain. From the following model we can get some clues:

$$
\begin{array}{r}
\Pi_{r}=P D T-S-P_{s} D T-\int_{0}^{T} h D(T-t) d t \\
+k_{i} \int_{0}^{M} P_{s} D T I_{r} d t-\left(1-k_{i}\right) P_{s} D T I_{b} M, \\
\Pi_{s}=P_{s} D T-C D T-k_{i} P_{s} D T I_{s} M,
\end{array}
$$

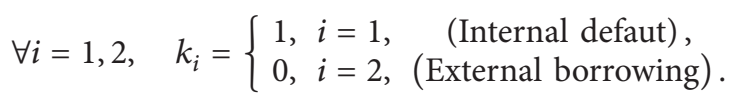

We analyze this model by numerical method and give another new set of data to the parameters as below: $P_{s}=$ $\$ 4 /$ unit, $P=\$ 12 /$ unit, $S=\$ 300 /$ order, $\alpha=0.1, I_{r}=0.14 /$ year, $h=\$ 0.1 /$ unit, $D=15$ units, $I_{s}=0.08 /$ year, $I_{b}=0.04 /$ year, $C$ $=\$ 2 /$ unit, $M=1$ day, and $T=8.017$ days, then we can get Table 3.

From Table 3, we know that the first method is not only optimal but also the most difficult to realize. Next, the negative influence of the external borrowing on the supply chain's entire profit is small, but influence of the internal delay is the maximum. So we should take effective methods to reduce the retailer's delay. For example, the supplier can adopt

\begin{tabular}{|c|c|c|c|c|}
\hline \multirow{2}{*}{ Decision making } & \multirow{2}{*}{$k_{i}$} & \multicolumn{3}{|c|}{ Profit (\$) } \\
\hline & & Retailer & Supplier & Channel \\
\hline Cash on delivery & 1 & 613.836 & 240.51 & 854.346 \\
\hline Internal default & 0 & 626.436 & 202.0284 & 828.4644 \\
\hline External borrowing & - & 594.5952 & 240.51 & 835.1052 \\
\hline
\end{tabular}
certain measures to compensate for the retailer's loss caused by external borrowing, which also can balance both profits, decrease the loss of the fashion supply chain, and avoid the behavior of internal delay. So the effective method is to set up different credit period mechanisms for retailers.
TABle 3: The impact on three different payment methods to distribution supply chain profit.

\section{Conclusions}

This paper explores the retailer's maximum profit in fashion supply chains when it follows the rules of credit period. Comparing the result of this paper with the result of [38], we find that although the two papers establish and analyze the model from different aspects, the effect is the same. It is suggested that if the retailer pursues profit maximization with reason and integrity, it can achieve the same result as in cooperation. Then we draw three inspirations from this conclusion as follows. (1) It can be found that choosing discount price for retailer is not always the best solution, but instead they should take all influencing factors into consideration. (2) Sometimes retailer delaying paying for goods may not bring the effect of achieving the maximum profit and it is nothing better than duly selecting a discount policy. (3) Offering discount policy is not only beneficial for suppliers themselves but also beneficial for the entire fashion supply chain.

Based on the above empirical research, this paper puts forward the following suggestions for the retailer and supplier of fashion industry. For the policy, it is suggested that the government should improve the relevant legal system to strengthen the severe punishment for dishonest companies and to compensate for the loss of the damaged side. For suppliers, they should actively establish reasonable system of credit period, thereby stimulating retailers to purchase more goods and, as a result, accelerate the flow of capital to gain more profit. For retailers, facing a variety of credit systems, they should make a reasonable choice of credit payment mechanism through rigorous calculation and verification of the model as described herein, to determine the optimal inventory cycle. For both parties, they should work together to establish credibility and note the importance of cooperation, using scientific methods to reduce costs, share the risk, and maximize their profits without hurting the interests of the other partner. Following all the above suggestions, even though the two parties are not bound by contract to make cooperation, the same effect can be achieved as in cooperation. In fact, the ultimate cooperation referred to 
herein means that each of the parties abides by integrity and ethics and pursues reasonable profit maximization, while consciously safeguarding interests of both parties, so that they can achieve win-win cooperation with no bound from contract. Finally, the paper confirms that this cooperation can be realized.

\section{Definition of Parameters and Variables}

\author{
$P_{s}$ : Wholesale price \\ D: Product demand per unit time \\ $S$ : Ordering cost per cycle \\ $\alpha: \quad$ Discount rate of the price \\ $I_{s}$ : Capital rate of supplier opportunity cost \\ $I_{r}$ : Capital rate of retailer opportunity cost \\ $h$ : Inventory cost per unit time and unit product \\ $C$ : Unit cost \\ $P$ : Retail price \\ $T$ : Inventory cycle \\ $M_{i}$ : Credit period \\ $\Pi_{r}$ : Profit for the retailer \\ $\Pi_{s}:$ Profit for the supplier.
}

\section{Conflict of Interests}

The authors declare that there is no conflict of interests regarding the publication of this paper.

\section{Acknowledgments}

This work was supported by the National Natural Science Foundation of China (nos. 71102174 and 71372019), Beijing Higher Education Young Elite Teacher Project (no. YETP1173), Specialized Research Fund for Doctoral Program of Higher Education of China (no. 20111101120019), and Beijing Philosophy and Social Science Foundation of China (no. 11JGC106).

\section{References}

[1] Z. L. Cheng, J. H. Xiao, K. Xie, and X. L. Huang, "Optimal product quality of supply chain based on information traceability in fashion and textiles industry: an adverse logistics perspective," Mathematical Problems in Engineering, vol. 2013, Article ID 629363, 13 pages, 2013.

[2] M. Huang, X. W. Wang, F. Q. Lu, and H. L. Bi, "A coordination of risk management for supply chains organized as virtual enterprises," Mathematical Problems in Engineering, vol. 2013, Article ID 931690, 11 pages, 2013.

[3] H. J. Peng and M. H. Zhou, "Quantity discount supply chain model with fashion products and uncertain yields," Mathematical Problems in Engineering, vol. 2013, Article ID 895784, 11 pages, 2013.

[4] J.-T. Teng and K.-R. Lou, "Seller's optimal credit period and replenishment time in a supply chain with up-stream and down-stream trade credits," Journal of Global Optimization, vol. 53, no. 3, pp. 417-430, 2011.

[5] C. K. Jaggi, S. K. Goyal, and S. K. Goel, "Retailer's optimal replenishment decisions with credit-linked demand under permissible delay in payments," European Journal of Operational Research, vol. 190, no. 1, pp. 130-135, 2008.
[6] K. Pan, K. K. Lai, L. Liang, and S. C. H. Leung, "Two-period pricing and ordering policy for the dominant retailer in a twoechelon supply chain with demand uncertainty," Omega, vol. 37, no. 4, pp. 919-929, 2009.

[7] J. Yazar, "Evolving densities in continuous strategy games through particle simulations," Journal of Economic Interaction and Coordination, vol. 1, no. 2, pp. 171-187, 2006.

[8] B. Guo, "Price competition, price war and industry performance: China color TV industry as a case," China Industrial Economy, vol. 7, pp. 55-60, 2001.

[9] S. K. Goyal, "Economic order quantity under conditions of permissible delay in payment," Journal of the Operational Research Society, vol. 36, no. 4, pp. 335-338, 1985.

[10] C. K. Jaggi and S. P. Aggarwal, "Credit financing in economic ordering policies of deteriorating items," International Journal of Production Economics, vol. 34, no. 2, pp. 151-155, 1994.

[11] J. Kim, H. Hwang, and S. Shinn, "Optimal credit policy to increase supplier's profits with price-dependent demand functions," Production Planning and Control, vol. 6, no. 1, pp. 45-50, 1995.

[12] M. Khouja and A. Mehrez, "Optimal inventory policy under different supplier credit policies," Journal of Manufacturing Systems, vol. 15, no. 5, pp. 334-339, 1996.

[13] M.-C. Cheng, K.-R. Lou, L.-Y. Ouyang, and Y.-H. Chiang, "The optimal ordering policy with trade credit under two different payment methods," TOP, vol. 18, no. 2, pp. 413-428, 2011.

[14] A. M. M. Jamal, B. R. Sarker, and S. Wang, "Optimal payment time for a retailer under permitted delay of payment by the wholesaler," International Journal of Production Economics, vol. 66, no. 1, pp. 59-66, 2000.

[15] C.-T. Chang, L.-Y. Ouyang, and J.-T. Teng, "An EOQ model for deteriorating items under supplier credits linked to ordering quantity," Applied Mathematical Modelling, vol. 27, no. 12, pp. 983-996, 2003.

[16] K.-J. Chung and J.-J. Liao, "Lot-sizing decisions under trade credit depending on the ordering quantity," Computers and Operations Research, vol. 31, no. 6, pp. 909-928, 2004.

[17] K.-J. Chung, S. K. Goyal, and Y.-F. Huang, “The optimal inventory policies under permissible delay in payments depending on the ordering quantity," International Journal of Production Economics, vol. 95, no. 2, pp. 203-213, 2005.

[18] K.-J. Chung, "A theorem on the determination of economic order quantity under conditions of permissible delay in payments," Computers and Operations Research, vol. 25, no. 1, pp. 49-52, 1998.

[19] Y. Liping, H. Xiaoyuan, and L. Zhen, "Analysis of supply chain coordination with integrated contract of trade credit and quantity discount," in Proceedings of the Chinese Control and Decision Conference (CCDC '08), vol. 1, pp. 961-964, July 2008.

[20] C. H. Lee and B.-D. Rhee, "Trade credit for supply chain coordination," European Journal of Operational Research, vol. 214, no. 1, pp. 136-146, 2011.

[21] Y.-G. Zhong and Y.-W. Zhou, "The model and algorithm for determining optimal ordering/trade-credit policy of supply chains," Applied Mathematics and Computation, vol. 219, no. 8, pp. 3809-3825, 2012.

[22] C.-T. Chang, "Extended economic order quantity model under cash discount and payment delay," International Journal of Information and Management Sciences, vol. 13, no. 3, pp. 57-69, 2002. 
[23] Y.-F. Huang, "Optimal retailer's ordering policies in the EOQ model under trade credit financing," Journal of the Operational Research Society, vol. 54, no. 9, pp. 1011-1015, 2003.

[24] S. W. Shinn and H. Hwang, "Optimal pricing and ordering policies for retailers under order-size-dependent delay in payments," Computers and Operations Research, vol. 30, no. 1, pp. 35-50, 2003.

[25] Y.-F. Huang, "Retailer's inventory policy under supplier's partial trade credit policy," Journal of the Operations Research Society of Japan, vol. 48, no. 3, pp. 173-182, 2005.

[26] L.-Y. Ouyang, J.-T. Teng, K.-W. Chuang, and B.-R. Chuang, "Optimal inventory policy with noninstantaneous receipt under credit credit," International Journal of Production Economics, vol. 98, no. 3, pp. 290-300, 2005.

[27] K.-J. Chung and J.-J. Liao, "The optimal ordering policy in a DCF analysis for deteriorating items when trade credit depends on the order quantity," International Journal of Production Economics, vol. 100, no. 1, pp. 116-130, 2006.

[28] K.-J. Chung and J.-J. Liao, "The optimal ordering policy of the EOQ model under trade credit depending on the ordering quantity from the DCF approach," European Journal of Operational Research, vol. 196, no. 2, pp. 563-568, 2009.

[29] S. S. Sana and K. S. Chaudhuri, "A deterministic EOQ model with delays in payments and price-discount offers," European Journal of Operational Research, vol. 184, no. 2, pp. 509-533, 2008.

[30] Y.-F. Huang, "Buyer's optimal ordering policy and payment policy under supplier credit," International Journal of Systems Science, vol. 36, no. 13, pp. 801-807, 2005.

[31] K.-J. Chung and Y.-F. Huang, "The optimal cycle time for EPQ inventory model under permissible delay in payments," International Journal of Production Economics, vol. 84, no. 3, pp. 307-318, 2003.

[32] C.-T. Chang and J.-T. Teng, "Retailer's optimal ordering policy under supplier credits," Mathematical Methods of Operations Research, vol. 60, no. 3, pp. 471-483, 2004.

[33] Y.-F. Huang, "Economic order quantity under conditionally permissible delay in payments," European Journal of Operational Research, vol. 176, no. 2, pp. 911-924, 2007.

[34] J. Li and L. Liu, "Supply chain coordination with quantity discount policy," International Journal of Production Economics, vol. 101, no. 1, pp. 89-98, 2006.

[35] Y. Liping and H. Xiaoyuan, "Analysis of coordination and profit sharing with trade credit in supply chain," in Proceedings of the 21st Chinese Control and Decision Conference (CCDC '09), vol. 1, pp. 1978-1981, June 2009.

[36] C.-H. Su, L.-Y. Ouyang, C.-H. Ho, and C.-T. Chang, "Retailer's inventory policy and supplier's delivery policy under twolevel trade credit strategy," Asia-Pacific Journal of Operational Research, vol. 24, no. 5, pp. 613-630, 2007.

[37] M.-C. Cheng, C.-T. Chang, and L.-Y. Ouyang, "The retailer's optimal ordering policy with trade credit in different financial environments," Applied Mathematics and Computation, vol. 218, no. 19, pp. 9623-9634, 2012.

[38] C.-H. Ho, L.-Y. Ouyang, and C.-H. Su, "Optimal pricing, shipment and payment policy for an integrated supplier-buyer inventory model with two-part trade credit," European Journal of Operational Research, vol. 187, no. 2, pp. 496-510, 2008. 


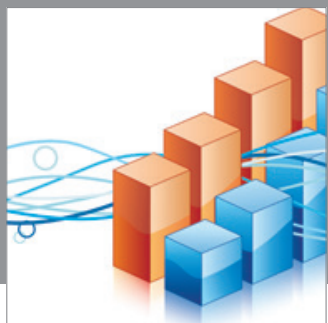

Advances in

Operations Research

mansans

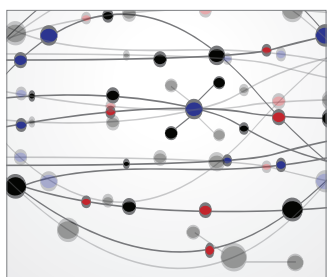

The Scientific World Journal
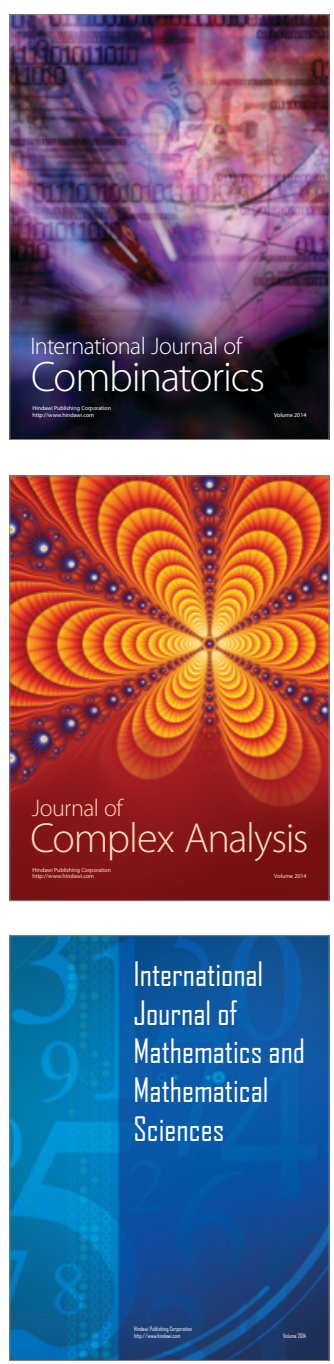
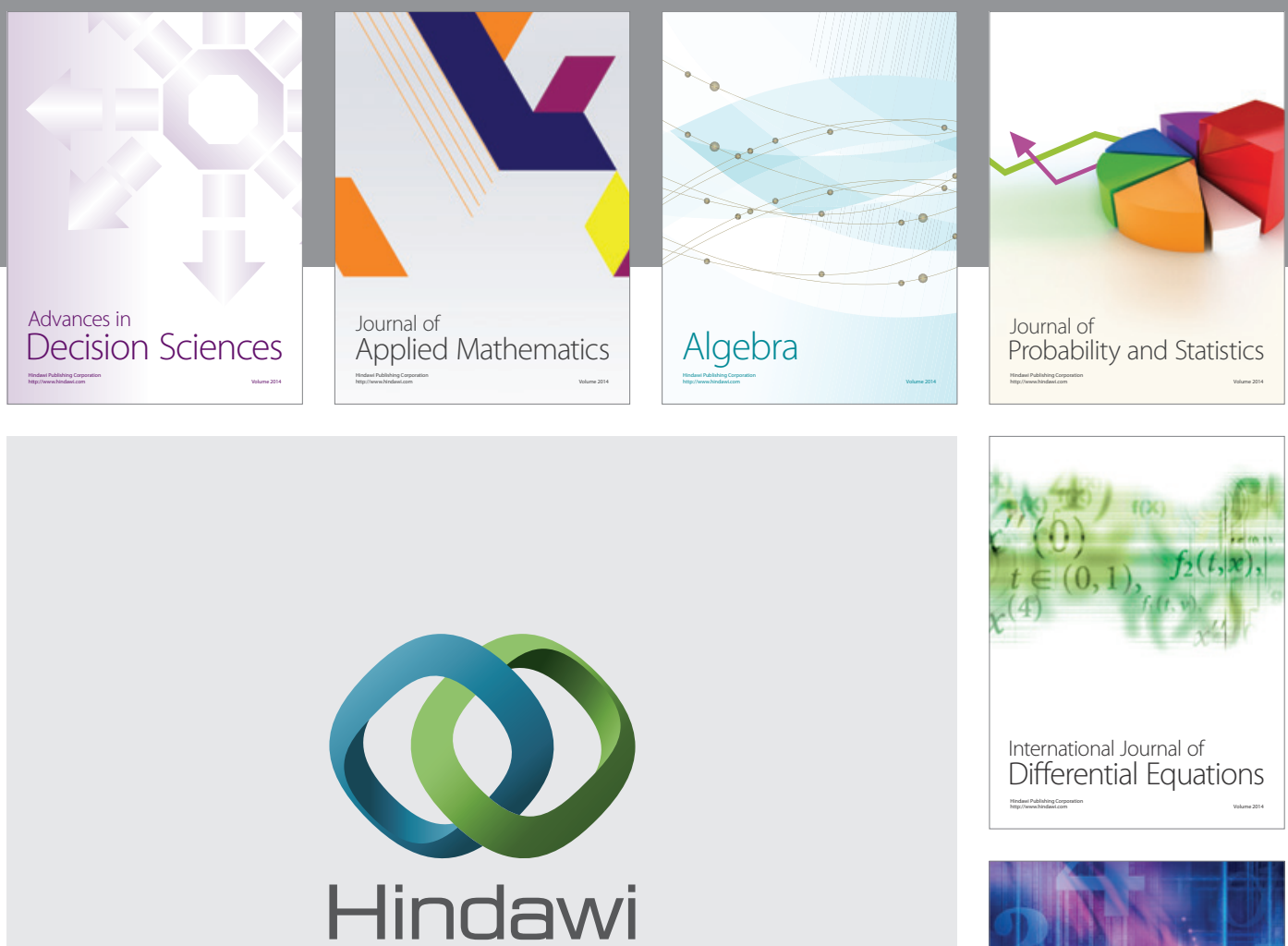

Submit your manuscripts at http://www.hindawi.com
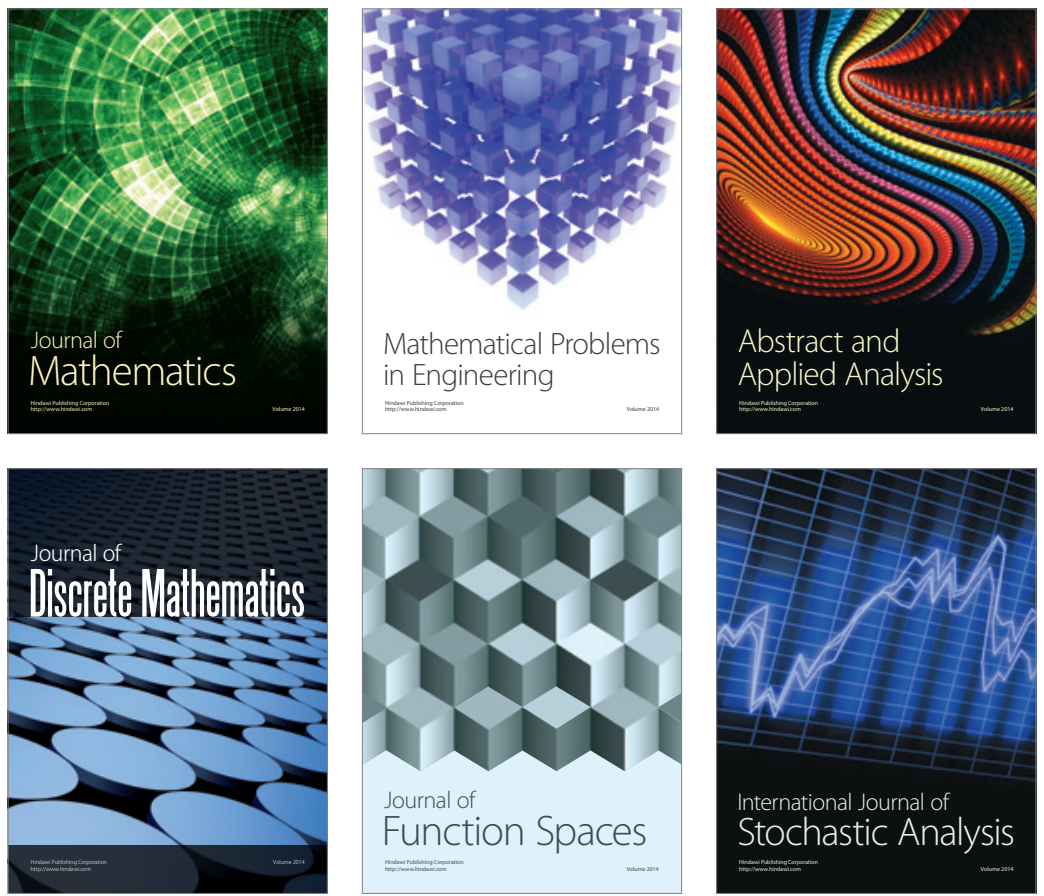

Journal of

Function Spaces

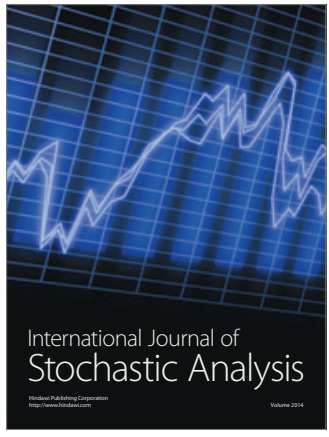

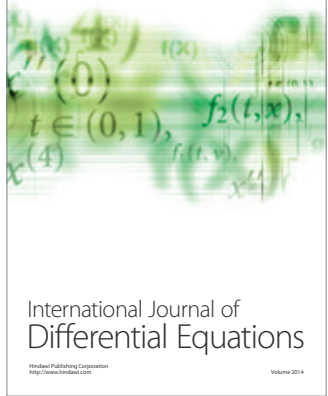
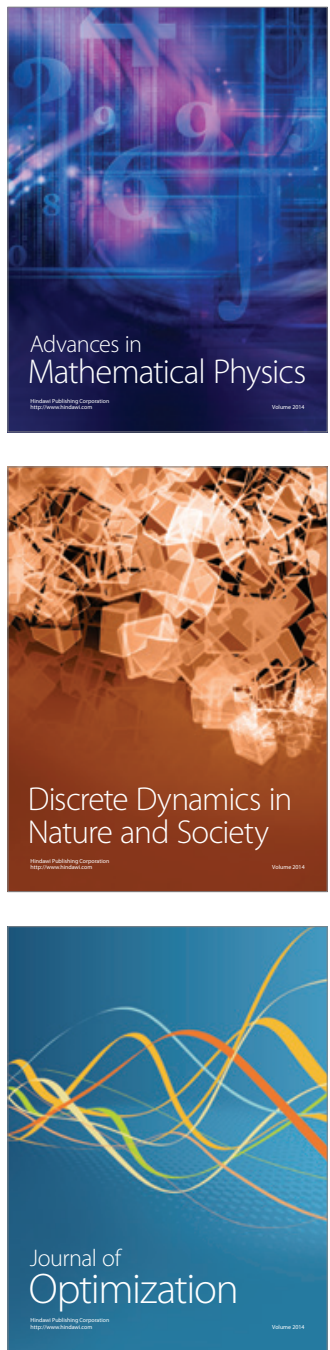